\title{
Socioeconomic and psychosocial predictors of dental healthcare use among Brazilian preschool children
}

\author{
Rômulo Vaz Machry ${ }^{1}$, Simone Tuchtenhagen ${ }^{1}$, Bernardo Antonio Agostini ${ }^{1}$, Carlos Roberto da Silva Teixeira ${ }^{1}$, \\ Chaiana Piovesan ${ }^{2}$, Fausto Medeiros Mendes ${ }^{3}$ and Thiago Machado Ardenghi ${ }^{1 *}$
}

\begin{abstract}
Background: Disparities in utilization of oral healthcare services have been attributed to socioeconomic and individual behavioral factors. Parents' socioeconomic status, demographics, schooling, and perceptions of oral health may influence their children's use of dental services. This cross-sectional study assessed the relationships between socioeconomic and psychosocial factors and the utilization of dental health services by children aged $1-5$ years.

Methods: Data were collected through clinical exams and a structured questionnaire administered during the National Day of Children's Vaccination. A Poisson regression model was used to estimate prevalence ratios and 95\% confidence intervals.

Results: Data were collected from a total of 478 children. Only $112(23.68 \%)$ were found to have visited a dentist; $67.77 \%$ of those had seen the dentist for preventive care. Most (63.11\%) used public rather than private services. The use of dental services varied according to parental socioeconomic status; children from low socioeconomic backgrounds and those whose parents rated their oral health as "poor" used dental services less frequently. The reason for visiting the dentist also varied with socioeconomic status, in that children of parents with poor socioeconomic status and who reported their child's oral health as "fair/poor" were less likely to have visited the dentist for preventive care.
\end{abstract}

Conclusion: This study demonstrated that psychosocial and socioeconomic factors are important predictors of the utilization of dental care services.

Keywords: Dental care, Healthcare disparities, Oral health, Preschool children, Health perceptions

\section{Background}

Disparities in oral healthcare utilization have been attributed to socioeconomic and individual behavioral factors [1-5]. However, in most developing countries, data are scarce regarding children's use of dental care services [2].

In Brazil, the latest national population-based oral health study showed that $18.1 \%$ of children age 12 years had never visited a dentist [6]. The same study reported regional inequalities in the use of dental services indicating that the most economically developed regions had the

\footnotetext{
* Correspondence: thiardenghi@hotmail.com

'Department of Stomatology, Federal University of Santa Maria, UFSM, Rua Cel. Niederauer 917/208, Santa Maria, RS, Brazil

Full list of author information is available at the end of the article
}

highest proportion of children who had received dental care in the previous year. It is strongly recommended that children see a dentist as early as 6 months of age, and no later than 6 months after the first tooth erupts $[7,8]$. However, $77.9 \%$ of children in Brazil have never visited a dentist. Thus, identifying the determinants of the utilization of dental healthcare services is essential for the development and improvement of public health policies in this country $[9,10]$.

There is considerable evidence that the use of dental care services may be influenced by socioeconomic and psychosocial factors $[4,10]$. Previous studies have reported that parents' perceptions of their child's oral health could influence oral health decisions and patterns of healthcare

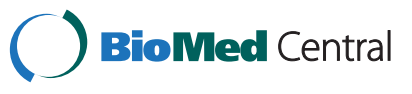


for children $[10,11]$. However, little data is available regarding the interaction of different predictors of dental care utilization in Brazilian preschool children [2].

This cross-sectional study assessed the relationships between socioeconomic and psychosocial factors and the utilization of dental health services by children aged $1-5$ years.

\section{Methods}

\section{Ethics}

This study was approved by the Ethics in Research Committee of the Federal University of Santa Maria in Santa Maria, Brazil. A letter was given to all parents explaining the aims of the study and asking for their consent for their children's participation. Consent was obtained from all parents before data collection.

\section{Sample}

A questionnaire-based survey was administered to parents of 1-5-year-old children from Santa Maria, Rio Grande do Sul, Brazil. Santa Maria is a medium-sized city located in the south of Brazil with an estimated population of 261,031 inhabitants, including 18,420 children aged $0-5$ years [12]. The following parameters were adopted to determine a sample size appropriate for assessing the association between the use of dental care services and various independent variables: $5 \%$ standard error, $80 \%$ power, $95 \%$ confidence interval, $10 \%$ non-response rate, 2:1 ratio of unexposed to exposed, and a prevalence ratio to be detected of at least 1.8. As we used multistage rather than simple random sampling, respondents tended to be clustered; thus, an adjustment for the sample design of 1.4 was adopted (design effect). The minimum sample size was estimated at 456 children.

\section{Data collection}

The study was conducted with children who attended the National Day of Children's Vaccination. More than $97 \%$ of children living in the city participated in the vaccination program. A sampling quota was selected from among all children who visited health centers in the municipality of Santa Maria. Health centers were used as sampling points because the city is divided into 5 administrative regions, and each has public health centers that are responsible for vaccinating the children who live in that area. For this study, all health centers that possessed a dental chair (15 health centers) were used as sample points. These were the largest health centers in the city; almost $90 \%$ of children visited these centers when this study was conducted. The sample was stratified according to the number of children in each area. During the survey, every fifth child in the queue for vaccination was invited to participate in the study. If their guardians did not consent to participation, the next child in the queue was selected. The same selection procedure was followed at all 15 participating health centers.

Data were collected through clinical examinations and a structured questionnaire administered by 15 researchers and 30 assistants who had been trained and calibrated prior to data collection. The training included theoretical explanations and informative discussions facilitated by clinical photographic examples. Subsequently, all examiners performed an examination of 60 exfoliated primary teeth set in arch models, aided by a dental operating light, 3-in-1 syringe, plane dental mirror, and a WHO periodontal probe. After the in vitro sessions, 10 children were examined twice by all examiners, at an interval of 1 week between examinations. Intra- and inter-examiner reliabilities were assessed; a total of 36 hours was spent on training and calibration. A benchmark dental examiner conducted the entire training and calibration process. Values for inter- and intra-observer agreement for ICDAS scores ranged from 0.86 to 0.92 and from 0.77 to 0.94 , respectively.

Children were examined while seated on a dental chair under conventional dental illumination. Visual examinations for ICDAS criteria were conducted with plane dental mirrors and WHO periodontal probes. Wet gauze pads, periodontal probes, toothbrushes, and dental floss were used to remove surface dental plaque [13]. As the ICDAS has demonstrated comparability with standard criteria (WHO) in an epidemiological survey of preschool children [14], we used the ICDAS cut-off point of 3 (0-2 sound, 3-6 carious) to calculate the number of decayed/missing/ filled teeth $(\mathrm{dmft})$. The prevalence of dental caries was considered as children with $\mathrm{dmft} \geq 1$.

A structured questionnaire was used to collect data for variables including age, children's gender and race, family income, parents' educational level, and health behaviors. Socioeconomic status was measured in terms of household income and parents' educational level. Household income was measured in terms of the Brazilian Minimum Wage (BMW), a common standard for this type of assessment, which corresponded to approximately $\$ 300$ US during the data collection period. The threshold used was based in the distribution of our data. Therefore, we used $1 \mathrm{BMW}$ as an income threshold because this value corresponded to the median value of our data. Educational level compared those fathers and mothers who had completed eight years of formal instruction, which corresponds to primary school in Brazil, with those who had completed only lower education (less than eight years of formal education). Parents answered questions about children's tooth brushing frequency; children who brushed their teeth 3 or more times per day were compared with those who brushed less often. Data on parents' perceptions of their child's oral health were measured by the following questions: (1) "Would 
you say that your child's oral health is 1 (excellent), 2 (good), 3 (fair), or 4 (poor)?" For analysis, responses were dichotomized into good (scores 1 and 2) and poor (scores 3 and 4) oral health. The feasibility of the questionnaire was previously assessed in a sample of 20 parents during the calibration process.

Our primary outcome was the use of dental services as measured by the question "Has your child ever visited the dentist?" When applicable, we inquired about the reason for the visit (preventive or non-preventive) and the type of service utilized (public or private).

\section{Statistical analyses}

Data were analyzed using STATA 12.0 (Stata Corp., College Station, TX, USA). Two outcomes were analyzed: prevalence of children who had never visited a dentist and the reason for the visit (preventive/non-preventive). Multivariate Poisson regression considering the cluster design was performed to assess the association between the predictor variables and the outcomes. A backward stepwise procedure was used to include or exclude explanatory variables in the models. Explanatory variables that correlated with each outcome with a $P$ value $\leq 0.20$ (unadjusted analyses) were included in the multivariate analysis. Only explanatory variables with a $P$ value $\leq 0.05$ after adjustment were selected for the final models.

\section{Results}

A total of 478 children-232 boys (48.54\%) and 246 girls (52.46\%)-participated in this study. Most were 36-59 months old (61.09\%) and of white skin color (79.29\%). Indicators of parental education and occupation were similar: nearly $56 \%$ of the fathers had or more eight years of education, and nearly $50 \%$ of the mothers were employed. Only 112 children (23.68\%) had visited the dentist; of those, $67.77 \%$ went for preventive reasons. Most (63.11\%) used public services. The prevalence of dental caries was $33.7 \%(\mathrm{dmft} \geq 1)$, and only 29 filled surfaces were observed in 11 teeth. No missing teeth were observed (Table 1).

Table 2 shows that the prevalence of children who had never visited a dentist was associated with children's age, maternal education, and frequency of tooth brushing. These associations remained significant in the multiple regression analysis. Older children were more likely than younger children to use dental services. In addition, children whose mothers had less than eight years of education were $13 \%$ more likely (PR: 1.13, 95\% CI: 1.02-1.24) to have never visited a dentist, in comparison to children whose mothers had eight or more years of education. Further, children who did not brush their teeth regularly were less likely to have visited the dentist than children who did (PR: 1.16, 95\% CI: 1.05-1.27).
Table 1 Sociodemographic and clinical characteristics of the sample

\begin{tabular}{|c|c|c|}
\hline Variable & $\mathbf{N}$ & $\%$ \\
\hline \multicolumn{3}{|l|}{ Child's gender } \\
\hline Male & 232 & 48.54 \\
\hline Female & 246 & 52.46 \\
\hline \multicolumn{3}{|l|}{ Child's age (months) } \\
\hline $12-35$ & 186 & 38.91 \\
\hline $36-59$ & 292 & 61.09 \\
\hline \multicolumn{3}{|l|}{ Child's skin color } \\
\hline White & 379 & 79.29 \\
\hline Non-White & 99 & 20.71 \\
\hline \multicolumn{3}{|l|}{ Household income } \\
\hline$>1 \mathrm{BMW}^{*}$ & 338 & 74.78 \\
\hline$\leq 1 \mathrm{BMW}^{*}$ & 114 & 25.22 \\
\hline \multicolumn{3}{|c|}{ Mother's level of education } \\
\hline$\geq 8$ years & 268 & 56.78 \\
\hline$<8$ years & 204 & 43.22 \\
\hline \multicolumn{3}{|c|}{ Father's level of education } \\
\hline$\geq 8$ years & 247 & 55.38 \\
\hline$<8$ years & 199 & 44.62 \\
\hline \multicolumn{3}{|c|}{ Does the child brush his/her teeth? } \\
\hline Yes & 434 & 90.99 \\
\hline No & 43 & 9.01 \\
\hline \multicolumn{3}{|l|}{ Children's dental caries } \\
\hline $\mathrm{dmft}=0$ & 317 & 66.32 \\
\hline$d m f t \geq 1$ & 161 & 33.68 \\
\hline \multicolumn{3}{|c|}{ Children's previous visit to the dentist } \\
\hline Yes & 112 & 23.68 \\
\hline No & 361 & 76.32 \\
\hline \multicolumn{3}{|l|}{ Reason for dental visit } \\
\hline Preventive & 82 & 67.77 \\
\hline Others than preventive & 39 & 32.23 \\
\hline \multicolumn{3}{|c|}{ Type of healthcare system } \\
\hline Private & 45 & 36.89 \\
\hline Public & 77 & 63.11 \\
\hline
\end{tabular}

$B M W$ Brazilian minimum wage; values lower than 478 due to missing data.

The association between the use of dental care services for non-preventive reasons and predictor variables is shown in Table 3. Low income, the presence of caries, and poor parent-perceived child oral health were associated with the prevalence of dental care use for treatment reasons even after adjustment for other covariates. Children from low-income families were more likely to have visited the dentist for treatment rather than preventive reasons (PR: 1.67, 95\% CI: 1.05-2.66). Children with dental caries used dental care services for non-preventive reasons 2.37 
Table 2 Child's dental visit and associated factors (prevalence ratio: $95 \% \mathrm{Cl}$ )

\begin{tabular}{|c|c|c|}
\hline \multirow[t]{2}{*}{ Variables } & \multicolumn{2}{|c|}{ Have never gone to the dentist } \\
\hline & PR $(95 \% \mathrm{Cl})$ & $\mathrm{PR}_{\text {adj. }}(95 \% \mathrm{Cl})$ \\
\hline Child's gender & $p=0.17$ & *** \\
\hline Male & 1 & \\
\hline Female & $1.07(0.97-1.17)$ & \\
\hline Child's age (months) & $p<0.001$ & $p<0.001$ \\
\hline $12-35$ & 1 & 1 \\
\hline $36-59$ & $0.84(0.76-0.92)$ & $0.84(0.76-0.93)$ \\
\hline Child's skin color & $p=0.56$ & $* *$ \\
\hline White & 1 & \\
\hline Non-White & $0.96(0.84-1.10)$ & \\
\hline Household income & $p=0.14$ & $* *$ \\
\hline$>1 \mathrm{BMW}^{*}$ & 1 & \\
\hline$\leq 1 \mathrm{BMW}^{*}$ & $1.08(0.97-1.21)$ & \\
\hline Mother's level of education & $p=0.02$ & $p=0.02$ \\
\hline$\geq 8$ years & 1 & 1 \\
\hline$<8$ years & $1.09(1.02-1.25)$ & $1.13(1.02-1.24)$ \\
\hline Father's level of education & $p=0.10$ & $* *$ \\
\hline$\geq 8$ years & 1 & \\
\hline$<8$ years & $1.09(0.98-1.21)$ & \\
\hline Does child brush teeth? & $p=0.00$ & $p=0.00$ \\
\hline Yes & 1 & 1 \\
\hline No & $1.28(1.17-1.40)$ & $1.16(1.05-1.27)$ \\
\hline Children's dental caries & $p=0.15$ & $* *$ \\
\hline $\mathrm{dmft}=0$ & 1 & \\
\hline $\mathrm{dmft} \geq 1$ & $0.92(0.82-1.03)$ & \\
\hline $\begin{array}{l}\text { Parents' perception of child's } \\
\text { oral health }\end{array}$ & $p=0.38$ & $* *$ \\
\hline Good/excellent & 1 & \\
\hline Fair/poor & $0.91(0.74-1.12)$ & \\
\hline
\end{tabular}

$p$ Wald statistics, $B M W$ Brazilian minimum wage, $P R$ prevalence ratio, $P R_{\text {adj }}$ adjusted prevalence ratio; $95 \% \mathrm{Cl} 95 \%$ confidence interval. **Variables not fitted in the final multiple model after the adjustment.

times more often than their counterparts without caries. Moreover, the probability of having visited the dentist for non-preventive reasons was 1.70 times higher for children with "poor" parent-perceived oral health compared to those with "good" parent-perceived oral health.

\section{Discussion}

We assessed the association between the use of dental care services and various psychosocial and socioeconomic variables. Overall, our results demonstrated that a high proportion of preschool children in Brazil had never visited a dentist, and that psychosocial and socioeconomic variables were significant predictors of dental service utilization.
Table 3 Reason for the dental visit and associated factors (prevalence ratio: $95 \% \mathrm{Cl}$ )

\begin{tabular}{|c|c|c|}
\hline \multirow[t]{2}{*}{ Variables } & \multicolumn{2}{|c|}{$\begin{array}{l}\text { Reason for the visit (other than } \\
\text { preventive) }\end{array}$} \\
\hline & PR $(95 \%$ Cl) & $\mathrm{PR}_{\text {adj. }}(95 \% \mathrm{Cl})$ \\
\hline Child's gender & $p=0.67$ & $* *$ \\
\hline Male & 1 & \\
\hline Female & $0.89(0.53-1.52)$ & \\
\hline Child's age (months) & $p=0.16$ & ** \\
\hline $12-35$ & 1 & \\
\hline $36-59$ & $1.73(0.81-3.73)$ & \\
\hline Child's skin color & $p=0.21$ & ** \\
\hline White & 1 & \\
\hline Non-White & $1.40(0.8-2.41)$ & \\
\hline Household income & $p=0.00$ & $p=0.03$ \\
\hline$>1 \mathrm{BMW}^{*}$ & 1 & 1 \\
\hline$\leq 1 \mathrm{BMW}^{*}$ & $0.71(0.57-0.89)$ & $1.67(1.05-2.66$ \\
\hline Mother's level of education & $p=0.33$ & $* *$ \\
\hline$\geq 8$ years & 1 & \\
\hline$<8$ years & $1.29(0.77-2.17)$ & \\
\hline Father's level of education & $p=0.13$ & $* *$ \\
\hline$\geq 8$ years & 1 & \\
\hline$<8$ years & $0.62(0.34-1.15)$ & \\
\hline Does child brush teeth? & $p=0.08$ & $* *$ \\
\hline Yes & 1 & \\
\hline No & $2.13(0.91-4.96)$ & \\
\hline Children's dental caries & $p=0.00$ & $p=0.01$ \\
\hline $\mathrm{dmft}=0$ & 1 & 1 \\
\hline $\mathrm{dmft} \geq 1$ & $2.98(1.67-5.33)$ & $2.37(1.31-4.30$ \\
\hline $\begin{array}{l}\text { Parents' perception of child's } \\
\text { oral health }\end{array}$ & $p=0.00$ & $p=0.02$ \\
\hline Good/excellent & 1 & 1 \\
\hline Fair/poor & $2.88(1.79-4.63)$ & $1.70(1.07-2.70$ \\
\hline
\end{tabular}

$p$ Wald statistics, $B M W$ Brazilian minimum wage, $P R$ prevalence ratio, $P R_{\text {adj }}$ adjusted prevalence ratio; $95 \% \mathrm{Cl} 95 \%$ confidence interval. ${ }^{* *}$ Variables not fitted in the final multiple model after the adjustment.

The low use of oral healthcare services in our study (23.68\%) was similar to that found by Ardenghi [2] in the same population in 2010, but higher than that found by Kramer et al. [9], who reported that only $13.3 \%$ of their sample of children had already consulted a dentist. Our results showed that a larger proportion of older than younger children used dental services. These findings support those of previous studies, and can be attributed to the cumulative effect of oral problems as children grow. Another explanation for this phenomenon is insufficient knowledge about the importance of early preventive dental care $[2,15,16]$. It is important to investigate whether this is associated with parents' perception of the need for a 
preventive appointment, or whether parents only bring their children to the dentist following the emergence of symptoms or presence of oral health problems $[9,17]$.

Socioeconomic status plays an important role in the utilization of health services $[4,9,17,18]$. Maternal education was associated with the use of dental services, indicating that lower knowledge of oral health leads to unhealthy behaviors and less interest in preventive treatment $[2,4]$. Education can lead people to be more health-conscious, and helps them make better and healthier lifestyle choices [19].

This study showed that children who did not brush their teeth were less likely to regularly visit the dentist than those who did; this can be explained by the absence of a preventive dental healthcare policy [9]. However, one may argue that the relationship could be considered in the inverse direction. In fact, children who did not visit the dentist were found to have unhealthy behaviors regarding tooth brushing.

Mothers' perception of their child's OHRQoL was associated with the utilization of dental services for treatment, confirming the notion that greater oral health need (perceived or normative) is an important predictor of the use of dental health services in preschool children $[17,20]$. This is in agreement with observations by Sohn [21]. Caregivers' unfavorable perception of their children's oral health motivates them to seek dental care for them [17]. The presence of untreated dental caries in children is associated with parents' perception that their children's oral health is poor, irrespective of their socioeconomic status $[10,22,23]$. Thus, a poor parental perception of children's health can be used as a measure of dental care need.

Dental visits for non-preventive reasons are directly related to the presence of dental caries. The utilization of dental services by children and adolescents is often driven by the presence of pain $[10,24]$, which is a consequence of untreated dental caries.

Data from this study must be assessed with caution. Our study employed a cross-sectional design, which pre-empts inferences regarding causality and temporal relationships between variables; thus, longitudinal studies should be conducted to investigate this issue. The possibility of recall bias is also a concern when working with questionnaires; however, the effect of this bias is not expected to be significant since self-reported dental care has been found to be a valid measure of dental care use across different socioeconomic strata [25]. In addition, one could argue that we did not use a validated questionnaire to measure the children's oral health-related quality of life. However, studies have shown that the single-item perceived oral health rating is related to other self-reported measures of oral health, such as multi-item indicators [26]. Moreover, this methodology was used in a previous study and is considered valid [27]. Thus, a single-item rating of perceived oral health is particularly appropriate for obtaining information from children's parents. All respondents to our questionnaire were parents, but we have no exact data on the relative proportion of mothers and fathers. However, as more than $90 \%$ of respondents were mothers, we believed that this issue did not influence our results.

\section{Conclusions}

In conclusion, this study demonstrated that psychosocial and socioeconomic factors are important predictors of the use of dental care services. Public health policy-makers should assess these variables and devote resources to eliminate the sources of this inequity in the use of dental services, thereby improving population health.

\section{Abbreviations}

OHRQoL: Oral health-related quality of life; WHO: World Health Organization; ECOHIS: Early childhood impact scale; PR: Prevalence ratio; Cl: Confidence interval.

\section{Competing interests}

The authors declare that they have no competing interests.

\section{Authors' contributions}

RMV, BAA, CRST, ST and CP assisted in data collection and writing the manuscript. TMA and FMM performed all statistical analyses, revised the manuscript, and supervised the study. All authors have read and approved the final manuscript.

\section{Acknowledgements}

The authors would like to thank all of the participating children and parents for their cooperation, and the Municipal Health Authorities of Santa Maria, Rio Grande do Sul, for the information and authorizations related to this study.

\section{Author details}

'Department of Stomatology, Federal University of Santa Maria, UFSM, Rua Cel. Niederauer 917/208, Santa Maria, RS, Brazil. ${ }^{2}$ Centro Universitário Franciscano (UNIFRA), Santa Maria, RS, Brazil. ${ }^{3}$ Department of Pediatric Dentistry, University of São Paulo, USP-SP, São Paulo, Brazil.

Received: 7 July 2013 Accepted: 29 October 2013

Published: 31 October 2013

\section{References}

1. Antunes $J \mathrm{~L}$, Jahn $\mathrm{GM}$, de Camargo MA: Increasing inequalities in the distribution of dental caries in the Brazilian context in Finland. Community Dent Health 2005, 22:94-100.

2. Ardenghi TM, Vargas-Ferreira F, Piovesan C, Mendes FM: Age of first dental visit and predictors for oral healthcare utilisation in preschool children. Oral Health Prev Dent 2012, 10:17-27.

3. Fisher MA, Mascarenhas AK: Does Medicaid improve utilization of medical and dental services and health outcomes for Medicaid-eligible children in the United States? Community Dent Oral Epidemiol 2007, 35:263-271.

4. Noro LR, Roncalli AG, Mendes Junior Fl, Lima KC: Use of dental care by children and associated factors in Sobral, Ceara State, Brazil. Cad Saude Publica 2008, 24:1509-1516.

5. Pizarro V, Ferrer M, Domingo-Salvany A, Benach J, Borrell C, Pont A, Schiaffino A, Almansa J, Tresserras R, Alonso J: The utilization of dental care services according to health insurance coverage in Catalonia (Spain). Community Dent Oral Epidemiol 2009, 37:78-84.

6. Brasil: Projeto SBBrasil 2010 - Resultados Principais. In Book Projeto SBBrasil 2010 - Resultados Principais. Edited by Editor ed.^eds. City: Ministério da Saúde; 2010. 
7. American Academy of Pediatric Dentistry reference manual 2007-2008. Pediatr Dent 2007, 29:1-271.

8. Ismail Al, Nainar SM, Sohn W: Children's first dental visit: attitudes and practices of US pediatricans and family physicians. Pediatr Dent 2003, 25:425-430.

9. Kramer PF, Ardenghi TM, Ferreira S, Fischer Lde A, Cardoso L, Feldens CA: Use of dental services by preschool children in Canela, Rio Grande do Sul State, Brazil. Cad Saude Publica 2008, 24:150-156.

10. Piovesan C, Antunes JL, Guedes RS, Ardenghi TM: Influence of selfperceived oral health and socioeconomic predictors on the utilization of dental care services by schoolchildren. Braz Oral Res 2011, 25:143-149.

11. Jokovic A, Locker D, Guyatt G: How well do parents know their children? Implications for proxy reporting of child health-related quality of life. Qual Life Res 2004, 13:1297-1307.

12. IBGE: CENSO 2010. In Book CENSO 201. Edited by Editor ed.^eds. City: Instituto Brasileiro de Geografia e Estatística; 2010.

13. Ismail Al, Sohn W, Tellez M, Amaya A, Sen A, Hasson H, Pitts NB: The International Caries Detection and Assessment System (ICDAS): an integrated system for measuring dental caries. Community Dent Oral Epidemiol 2007, 35:170-178.

14. Braga MM, Oliveira LB, Bonini GA, Bonecker M, Mendes FM: Feasibility of the International Caries Detection and Assessment System (ICDAS-II) in epidemiological surveys and comparability with standard World Health Organization criteria. Caries Res 2009, 43:245-249.

15. Al-Shalan TA: Factors affecting Saudi parents' perception of their children's first dental visit. J Contemp Dent Pract 2003, 4:54-66.

16. Savage MF, Lee JY, Kotch JB, Vann WF Jr: Early preventive dental visits: effects on subsequent utilization and costs. Pediatrics 2004, 114:e418-e423.

17. Goettems ML, Ardenghi TM, Demarco FF, Romano AR, Torriani DD: Children's use of dental services: influence of maternal dental anxiety, attendance pattern, and perception of children's quality of life. Community Dent Oral Epidemiol 2012, 40:451-458.

18. Araujo CS, Lima Rda C, Peres MA, Barros AJ: Use of dental services and associated factors: a population-based study in southern Brazil. Cad Saude Publica 2009, 25:1063-1072

19. Braveman PA, Cubbin C, Egerter S, Chideya S, Marchi KS, Metzler M, Posner S: Socioeconomic status in health research: one size does not fit all. JAMA 2005, 294:2879-2888.

20. Medina-Solis CE, Maupome G, Avila-Burgos L, Hijar-Medina M, SegoviaVillanueva A, Perez-Nunez R: Factors influencing the use of dental health services by preschool children in Mexico. Pediatr Dent 2006, 28:285-292.

21. Sohn W, Ismail A, Amaya A, Lepkowski J: Determinants of dental care visits among low-income African-American children. J Am Dent Assoc 2007, 138:309-318. quiz 395-396, 398

22. Cushing AM, Sheiham A, Maizels J: Developing socio-dental indicators-the social impact of dental disease. Community Dent Health 1986, 3:3-17.

23. Reisine ST, Bailit $\mathrm{HL}$ : Clinical oral health status and adult perceptions of oral health. Soc Sci Med Med Psychol Med Sociol 1980, 14A:597-605.

24. Villalobos-Rodelo JJ, Medina-Solis CE, Maupome G, Lamadrid-Figueroa H, Casanova-Rosado AJ, Casanova-Rosado JF, Marquez-Corona Mde L: Dental needs and socioeconomic status associated with utilization of dental services in the presence of dental pain: a case-control study in children. J Orofac Pain 2010, 24:279-286.

25. Gillbert GH, Rose JS, Shelton BJ: A prospective study of the validity of data on self-reported dental visits. Community Dent Oral Epidemiol 2002, 30:352-362.

26. Atchison KA, Dolan TA: Development of the geriatric oral health assessment index. J Dent Educ 1990, 54:680-687.

27. Piovesan C, Marquezan M, Kramer PF, Bonecker M, Ardenghi TM: Socioeconomic and clinical factors associated with caregivers' perceptions of children's oral health in Brazil. Community Dent Oral Epidemiol 2010, 39:260-267.

\section{doi:10.1186/1472-6831-13-60}

Cite this article as: Machry et al:: Socioeconomic and psychosocial predictors of dental healthcare use among Brazilian preschool children. BMC Oral Health 2013 13:60.

\section{Submit your next manuscript to BioMed Central and take full advantage of:}

- Convenient online submission

- Thorough peer review

- No space constraints or color figure charges

- Immediate publication on acceptance

- Inclusion in PubMed, CAS, Scopus and Google Scholar

- Research which is freely available for redistribution 